\title{
Phase Analysis of the Cellulose Triacetate-Nitromethane System
}

\author{
Anna B. Shipovskaya, ${ }^{1}$ Natalia O. Gegel, ${ }^{1}$ Sergei L. Shmakov, ${ }^{1}$ and Sergei Yu. Shchyogolev ${ }^{2}$ \\ ${ }^{1}$ Institute of Chemistry, Saratov State University, 83 Ulitsa Astrakhanskaya, Saratov 410012, Russia \\ ${ }^{2}$ Institute of Biochemistry and Physiology of Plants and Microorganisms, 13 Prospect Entuziastov, Saratov 410049, Russia
}

Correspondence should be addressed to Anna B. Shipovskaya, shipovskayaab@rambler.ru

Received 31 March 2011; Revised 27 May 2011; Accepted 20 August 2011

Academic Editor: Jan-Chan Huang

Copyright ( 2012 Anna B. Shipovskaya et al. This is an open access article distributed under the Creative Commons Attribution License, which permits unrestricted use, distribution, and reproduction in any medium, provided the original work is properly cited.

A comprehensive study was made on the cellulose triacetate-nitromethane system to explore its phase separation within ranges $2-$ 25 wt. $\%$ and $-5 \div+80^{\circ} \mathrm{C}$ by means of polarization light and electron microscopy, the turbidity spectrum method, differential thermal and X-ray analyses, and rheological techniques. The physical state of the polymer was identified within the phase coexistence boundaries on the phase diagram which included three types of phase separation (amorphous (with a UCST at $T_{\mathrm{cr}}=57^{\circ} \mathrm{C}$ and $\left.c_{\mathrm{cr}}=7.3 \mathrm{wt} . \%\right)$, crystal, and liquid crystal). The boundaries of the regions determining the coexistence of the liquid crystal (LC) and the partly crystal phase were found to be inside the region of amorphous liquid-liquid phase separation. For cellulose ester-solvent systems, this state diagram is the first experimental evidence for the possibility of coexistence of several phases with amorphous, LC, and crystal polymer ordering.

\section{Introduction}

The structure of polymer-solvent systems and their behavior in particular conditions are reflected/described by the corresponding state diagrams. The information contained therein determines the character of any observed structural transformations, most often connected with the appearance of new disperse phases $[1,2]$. Knowledge of the mechanism of phase separation kinetics opens ways to directly influence the system's morphology and, correspondingly, to design materials and products with desired properties.

However, drawing phase diagrams for polymeric systems based on cellulose esters is associated with serious experimental and theoretical difficulties. The structural and molecular heterogeneity of cellulose derivatives, their high molecular masses, diffusion coefficient low values, high viscosities of even moderately concentrated solutions, and specific intermolecular and molecule-solvent interactions hinder obtaining correct (consistent) data. This may lead to ambiguous or even contradictory conclusions on the state diagrams of the same (e.g., nitrocellulose-glycerol) systems, (for a detailed discussion, see [1]).

This work explores phase separation in the cellulose triacetate (CTA) nitromethane system. This system was chosen because of the wide practical application of CTA and the possibility of producing fibers and films with good physicomechanical properties (including low factors of unevenness and variation) from its nitromethane solutions or by means of nitromethane-vapor modification of the polymer $[3,4]$.

One version of the diagram of state of this system was plotted in [5] by means of the turbidity spectrum method [2, 6]. A sample obtained from Khimvolokno Corp. (Vladimir City, Russian Federation) was used, and the diagram showed phase separation regions of both liquid-liquid (with a UCST) and liquid-crystal type. The boundary curve of the system's absolute instability was named the "quasispinodal", since it was not tangent to the binodal at the apparent UCST (as it should according to the classical thermodynamics of solutions) but was located tens of degrees lower. This circumstance might be caused by long relaxation processes in the system with its high viscosity and, hence, natural restrictions of the thermokinetic approach used in this paper to draw the phase diagram. The methodology described in $[2,6]$ is for the location of configurative points at the true spinodal only for systems with relatively low viscosities, where the relaxation process rates are comparable with the phase separation ones. Except [5], no other information on 
the state diagram of the CTA-nitromethane system has been found by us in the literature.

We used a CTA sample that had its physicochemical characteristics close to those of the polymer from [5] but was produced at another industrial enterprise. To assess the type of phase separation (amorphous, crystal, etc.) and the equilibrium degree of the boundary curves obtained, the range of experimental and calculational methods used was widened, and special approaches were applied to allow for some features of the phase behavior of the system.

The aim of this work was to make a comprehensive analysis of phase separation in the CTA-nitromethane system and its properties both outside and inside the phase separation range, with identification of the polymer's phase state within the phase coexistence regions on the state diagram.

\section{Materials and Methods}

A commercial granulated CTA sample of wood origin (Khimvolokno Corp., Engels City, Russian Federation), used for the production of acetate fiber, was taken served as an object of our research. Its characteristics are as follows: acetylation degree, $62.2 \%$, viscosity-averaged molecular mass, $\bar{M}_{\eta}=70 \mathrm{kDa}$; ashness, 0.15 . The CTA sample was separated from its high- and low-molecular-weight fractions. According to our fractionation (sequential precipitation) data, the polymolecularity of the sample was rather low, with the range of most probable molecular masses being $60-80$ $\mathrm{kDa}$. Nitromethane (analytical grade) with $d=1.14 \mathrm{~g} / \mathrm{ml}$, b.p. $=101.2^{\circ} \mathrm{C}$, and m.p. $=-28.5^{\circ} \mathrm{C}$ was used as a low-molecularweight component. It is an electron donor, dipolar, and aprotic solvent [7] that preferably solvates hydroxylic groups in cellulose acetates $[8,9]$.

The CTA-nitromethane system was studied within a concentration range of $c=2-25 \mathrm{wt} . \%$ and a temperature range of $T=-5-80^{\circ} \mathrm{C}$. The research objects were prepared by swelling a weighed polymeric sample at room temperature for $24 \mathrm{~h}$ with subsequent dissolution on a water bath at $T=70-80^{\circ} \mathrm{C}$. Dissolution was monitored by polarization microscopy and was considered finished when no undissolved particles of the polymer were seen. The prepared systems were kept at room temperature under atmospheric pressure.

In every experiment, the composition of the solution/ mixture was constant and the temperature varied. Before optical and rheological measurements, the system had been thermostatted at $T=70-80^{\circ} \mathrm{C}$ for $1.0-1.5 \mathrm{~h}$ with subsequent cooling down to the temperature of the current experiment. The cooling rate was set according to the peculiarities of the technique used. In separate experiments, measurements were made at raising temperature.

Optical measurements were conducted on an MPSU1 polarization microscope equipped with a UKRT-3 temperature control and regulation tool. Photos were made with a Zenith camera with a 3-4 s exposition. The polarizer and analyzer were located so as to see a dark field for an isotropic (though optically active) solution. Phase separation was observed visually by changes in the system's morphology with a microscope (new-phase particles on a dark field).
First, at rapid cooling $\left(\approx 1^{\circ} \mathrm{C} / \mathrm{min}\right)$ of a layer of the solution $(\sim 1 \mathrm{~mm})$, the phase transition temperature was roughly estimated. Then, it was determined more precisely in the a $\pm 5^{\circ} \mathrm{C}$ region around the estimated value in the modes of stepwise lowering and increasing the temperature with at $\mathrm{a} \approx 1^{\circ} \mathrm{C} / \mathrm{h}$ rate and a duration of thermostatting of not shorter than $4-7 \mathrm{~h}$ at every temperature. This procedure was repeated until the discrepancies between the temperature values obtained in these two modes did not exceed $0.5^{\circ} \mathrm{C}$.

Absorbance was measured on an FRK-56 photoelectrocolorimeter within the wavelength range $\lambda=400-670 \mathrm{~nm}$. The solutions, after preliminary thermostatting at $70-80^{\circ} \mathrm{C}$, were quickly $\left(\approx 3-4^{\circ} \mathrm{C} / \mathrm{min}\right)$ cooled down to the desired temperature. During the subsequent thermostatting $(t=5-$ $8 \mathrm{~h})$, turbidity spectra were recorded. The phase conversion rate $V_{\tau}$ was estimated from those segments where the turbidity $\tau$ (variant 1 ) or induction period (variant 2 ) on the $\tau=f(t)$ dependence increased most rapidly at $\lambda=540 \mathrm{~nm}$, $T=$ const, and $c=$ const.

The stability boundary of the solution of the current concentration was determined by extrapolation of the temperature dependence of the turbidity increase rate $V_{\tau}(T)$ to zero. The extrapolation $V_{\tau}^{-1}(T) \rightarrow 0$ allowed finding the temperature of absolute instability of the system. The effective radius of particles $\bar{r}_{\lambda}$ was calculated according to $[2,6]$, with the relative refraction index being 1.07 . The optical activity of both phases was neglected.

Melting points were determined by differential thermal analysis (DTA) on a Kurnakov pyrometer with an $\mathrm{Al}_{2} \mathrm{O}_{3}$ reference and a heating rate of $1.5^{\circ} \mathrm{C} / \mathrm{min}$. Diffraction patterns of CTA (powder or film) were recorded by X-ray diffraction analysis at small angles on a DRON-3 diffractometer with $\mathrm{Cu}-\mathrm{K}_{\alpha}$ light at $U=22 \mathrm{kV}$ and $J_{a}=20 \mathrm{~mA}$.

Rheological studies were performed on a Reotest-1 viscometer within a shear stress range $\lg \sigma=1.7-2.7(\mathrm{~Pa})$. Deformations at every temperature were applied periodically, in fixed periods of time. Between these deformation cycles, the system was at rest in the working unit (the coaxial cylinders $\mathrm{H}$ ) of the viscometer under isobaric isothermal conditions.

Electron microscopic studies were conducted on EM5 and Tesla-242E electron microscopes. The solution was sprayed with a UZDN-1 ultrasound low-frequency disperser.

The spinodal was calculated within the framework of Flory-Huggins' lattice model [10] by the following equation:

$$
\chi_{1}=\frac{1}{2\left(1-v_{2}\right)}+\frac{1}{2 z v_{2}},
$$

where $\chi_{1}$ is the Flory-Huggins interaction parameter, $z$ is the average number of elementary units in a macromolecule $(z=$ $n / 2, n$ being the polymerization degree), and $v_{2}$ is the volume fraction of the second component (CTA) in the mixture.

The binodal for biphasic amorphous separation in the polymer-low-molecular-weight liquid system was approximated according to the algorithm described in [11], with the use of the experimentally found coordinates of configurative points. 


\section{Results and Discussion}

Our polarization microscopic observations showed that phase separation occurred in visually homogeneous (within the microscope field) CTA solutions in nitromethane heated up to $70-80^{\circ} \mathrm{C}$ - there arose light emitting particles (newphase centers) of primarily spherical shape. In the course of thermostatting at some $T$ the number of these newphase centers increased up to some limiting value within 1-6 hours (depending on the polymer concentration and temperature). Particle shape did not change. The lower was the $T$ inside the found concentration-temperature range of phase separation, the greater was the maximum size of the particles being formed. Figures $1(\mathrm{~b})-1(\mathrm{~d})$ provide photos reflecting the changes in the CTA-nitromethane solution morphology $(c=8 \mathrm{wt} . \%)$ at lowering temperature and in the course of thermostatting at a constant $T$.

When the temperature was raised, the disperse phase particles dissolved. The formation-dissolution temperature of the heterogeneous structure fixed in the cooling-heating mode was considered as the coordinate of the boundary configurative points on the state diagram. The set of such coordinates obtained for several $c$ was taken as the boundary curve of phase separation.

It should be noted that for polymer concentrations $\sim 5-$ $11 \mathrm{wt} \%$, the transition of the homogeneous system to its metastable state is preceded by the appearance of anisometric birefringent (in polarized light) fragments (Figure 1(a)). This could be regarded as a manifestation of fluctuation structures (which are not separate phases in their essence) owing to the critical retardation effect (with diffusion coefficient vanishing) ([2, pages 238-240], [12]). The shape of such long-lived heterophasic fluctuations differs from the usual quasispherical one, possibly because of intercompensation of the strong polymer-polymer and polymer-solvent interactions. Nitromethane, solvating a small quantity of the hydroxylic groups remaining in CTA, does not hinder the formation of frequent intermolecular contacts by the free acetate groups. Consequently, the weaker interactions, previously unnoticeable/negligible on the background of the stronger ones, are now given an opportunity to develop. In particular, at lowering temperature, the nitromethane solvation of the residual hydroxylic groups (which the intermolecular interaction is realized by) in CTA weakens. This promotes engagement of the critically frozen polymeric molecules into spongy anisotropic (nonspherical) aggregates-fluctuations, which are observed with a microscope during hours. The low rates of relaxation processes provide the longevity of such fluctuations.

However, another explanation for the appearance of these anisometric anisotropic formations is possible. For example, [13] theoretically justifies the possible formation of a lyotropic LC phase in the cellulose acetate-nitromethane system. Taking account of the relatively great sizes (comparable with those of the disperse-phase particles) of the birefringent formations, one can hypothesize the origination of particles of a highly ordered LC phase. However, as the LC particle formation rate is significantly lower than the amorphous particle formation rate, the kinetics observed with a polarization microscope at decreasing $T$ (Figures $1(\mathrm{~b})-1(\mathrm{~d}))$ reflect amorphous phase separation in the CTA-nitromethane system. Other possible evidence for the hypothesized superposition of two types of phase separations will be given below.

Allowing for some specific peculiarities (giant concentration fluctuations) of the system's transfer from its single-phase state to the range of phase separation, the turbidity spectrum method $[2,6]$ was also used for locating configurative points and for studying the kinetics of changes of the new-phase particle parameters in the metastable range. In this case, the turbidity caused by concentration fluctuations is set almost instantaneously and does not change in the future. Correspondingly only turbidity kinetics is experimentally measured which is related to the size changes of the new-phase particles [2].

Figure 2 presents an example of turbidity changes in time at fixed temperatures for the CTA-nitromethane system with a polymer concentration of $2 \mathrm{wt} \%$. For other compositions, the $\tau=f(t)$ dependences were similar. One can see that in a certain temperature range, $\tau$ sharply increased during thermostatting, and the average effective particle size $\bar{r}_{\lambda}$ increased also. Such a behavior, along with our polarization microscopy data, attests that phase separation occults by the mechanism of nuclei formation and growth of the new-phase particles.

Figure 3 shows typical (for solutions with $c \sim 2-7 \mathrm{wt} \%$ ) temperature dependences of both direct and inverse rates of phase separation increase (turbidity), calculated from the segments of both initial (the induction period) and intense changes of $\tau$. As temperature increased, $V_{\tau}$ decreased, which is characteristic of systems with an UCST. The geometrical loci with $V_{\tau}(T)=0$ and $V_{\tau}^{-1}(T)=0$ were taken as the binodal curve and the absolute instability curve (spinodal), respectively.

Within a certain concentration-temperature range, the growth of $\tau$ and $\bar{r}_{\lambda}$ began after an induction period. It turned out that for $c \sim 8-10 \mathrm{wt} \%$, the temperature dependences of both direct and inverse rates of turbidity increase, calculated by method 1 in the segment of intense growth of $\tau$ and the new-phase particles (Figure 4(a)), were similar to the $V_{\tau}=$ $f(T)$ curves obtained for lower concentration solutions (Figure 3). However, the temperature dependences of the rate determined from the induction period segment (i.e., at the first stage of phase separation) of the kinetic curve $\tau=f(t)(\operatorname{method} 2)$ were of extreme character (Figure 4(b)). Note that the temperatures obtained by extrapolation to zero of both left-hand and right-hand branches of the $V_{\tau}=f(T)$ curve with a maximum turned out to be almost equal to those obtained by the $V_{\tau}(T) \rightarrow 0$ and $V_{\tau}^{-1}(T) \rightarrow 0$ extrapolations for $V_{\tau}$, calculated by method 1 .

Such a different character of the temperature dependence of $V_{\tau}$ at different stages of phase separation gives evidence for the complex type of phase separation in the system. The $V_{\tau}(T)$ dependence is known to be represented by a smooth curve with no minima or maxima for the liquidliquid phase separation, where as for the liquid-crystal one, the function $V_{\tau}(T)$ is of extreme character $[2,12]$. In the latter case, the right-hand branch of the $V_{\tau}(T)$ dependence 


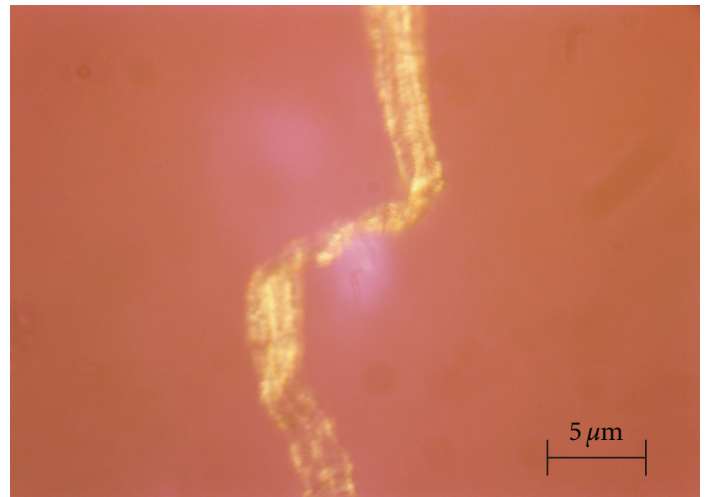

(a)

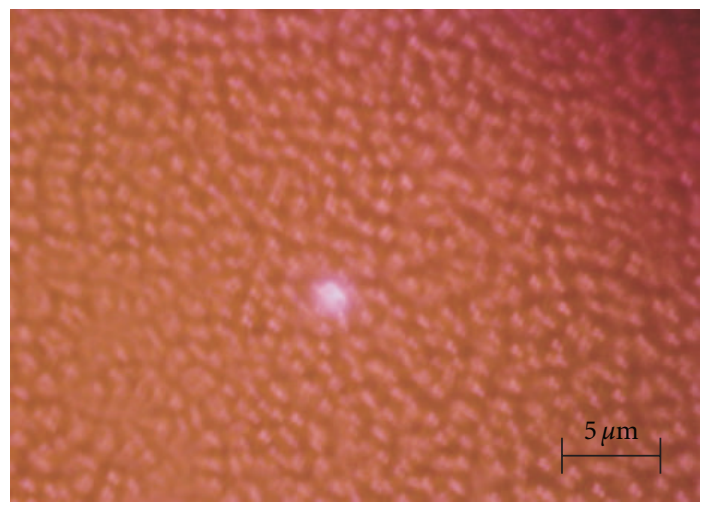

(c)

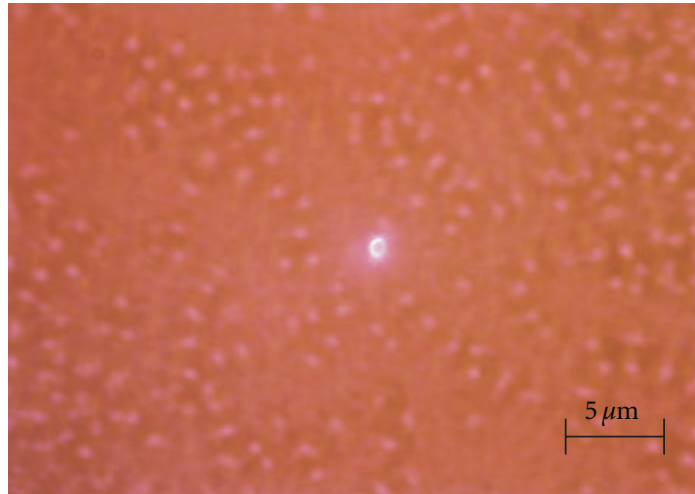

(b)

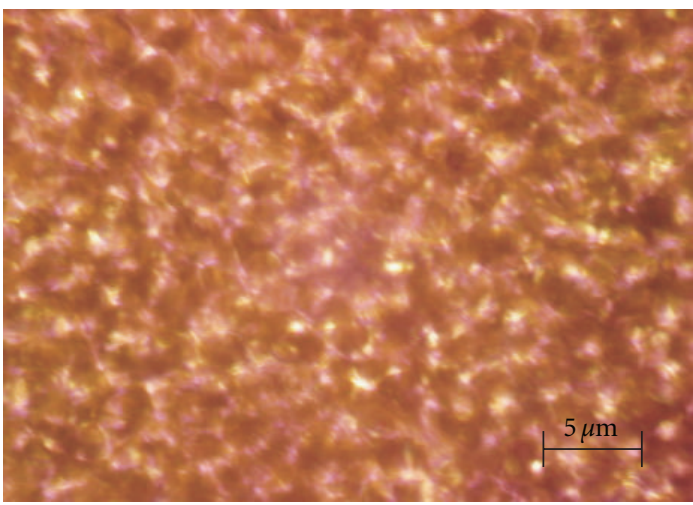

(d)

Figure 1: Morphology of the CTA-nitromethane system with a polymer concentration of $8 \mathrm{wt} \%$ at temperatures of $55^{\circ}$ (a), $50^{\circ}$ (b), (c), and $25^{\circ} \mathrm{C}(\mathrm{d})$ after thermostatting for $30 \mathrm{~min}(\mathrm{a}),(\mathrm{b}), 1 \mathrm{~h}(\mathrm{c})$, and $2 \mathrm{~h}(\mathrm{~d})$. The microphotos were made in polarized light.

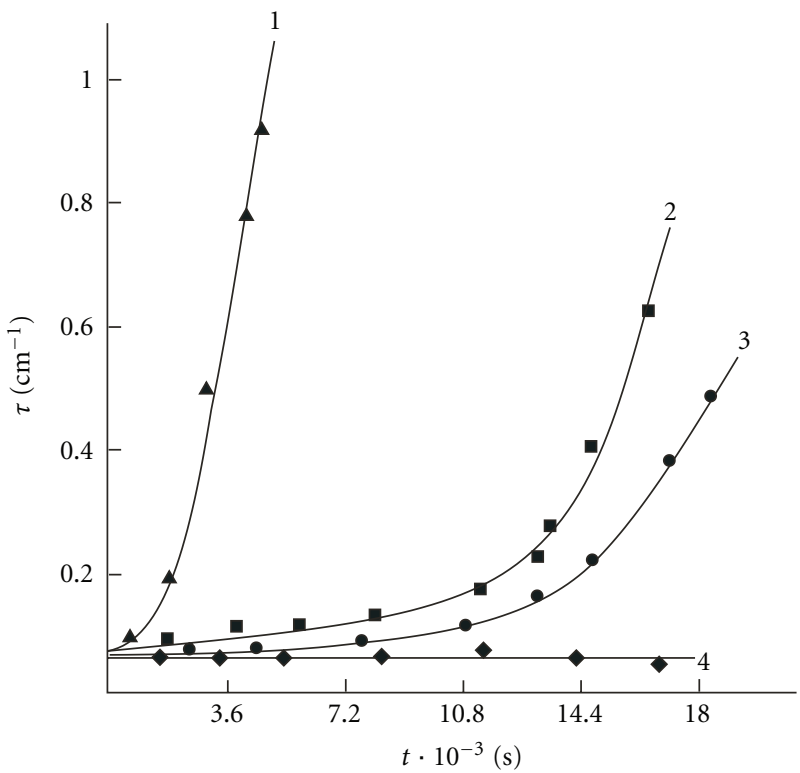

(a)

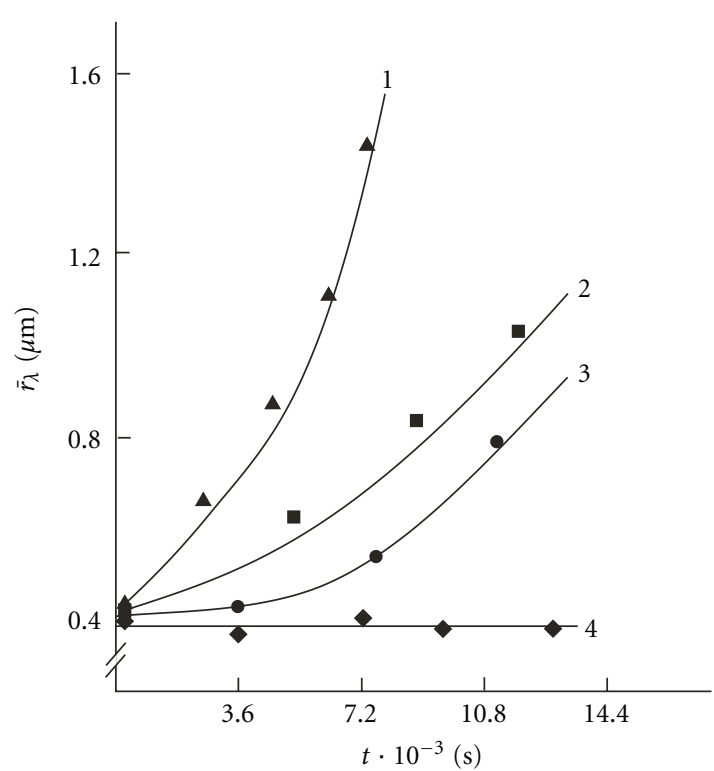

(b)

FIgURE 2: Kinetics of the turbidity $\tau$ at $\lambda=540 \mathrm{~nm}$ (a) and the particle size $\bar{r}_{\lambda}$ (b) for the CTA-nitromethane system with a polymer concentration of $2 \mathrm{wt} \%$ at temperatures of $-5^{\circ}(1), 8^{\circ}(2), 11^{\circ}(3)$, and $20^{\circ} \mathrm{C}(4)$. 


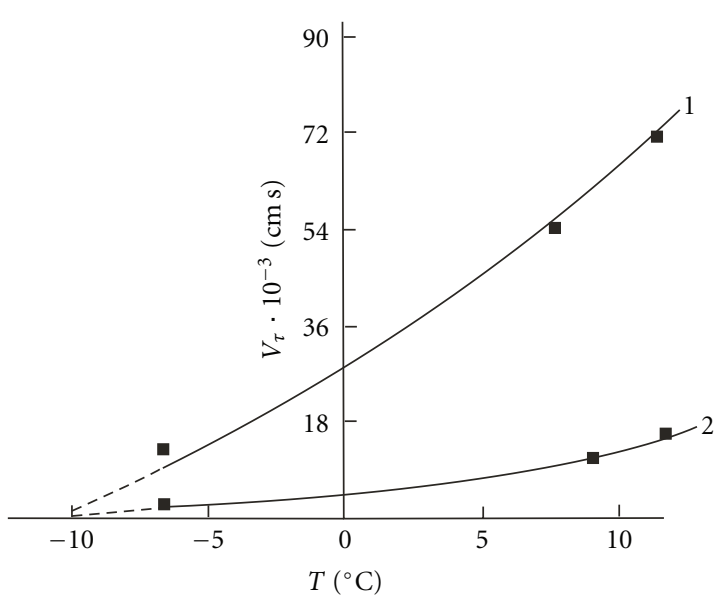

(a)

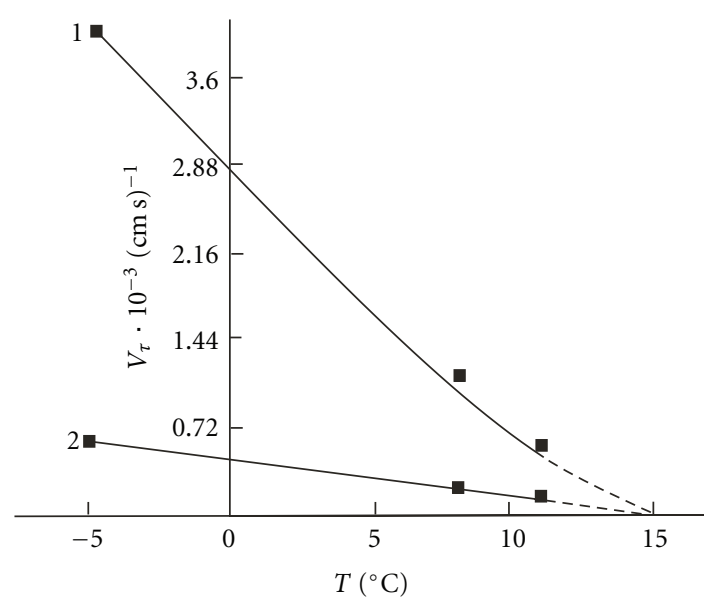

(b)

FIGURE 3: Estimation of the boundary temperatures of phase separation for the CTA-nitromethane system with a polymer concentration of $2 \mathrm{wt} \%$ by extrapolation of the direct (a) and inverse rates (b) of turbidity growth, calculated at the stage of intense $\tau$ changes (1, method 1 ) and from the initial fragment of the kinetic $\tau=f(t)$ curve (2, method 2).

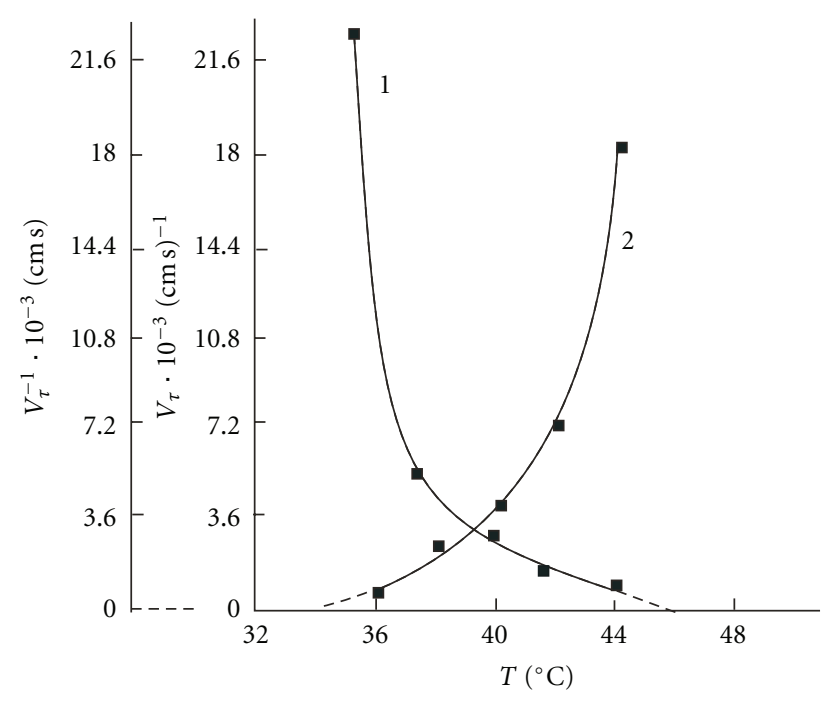

(a)

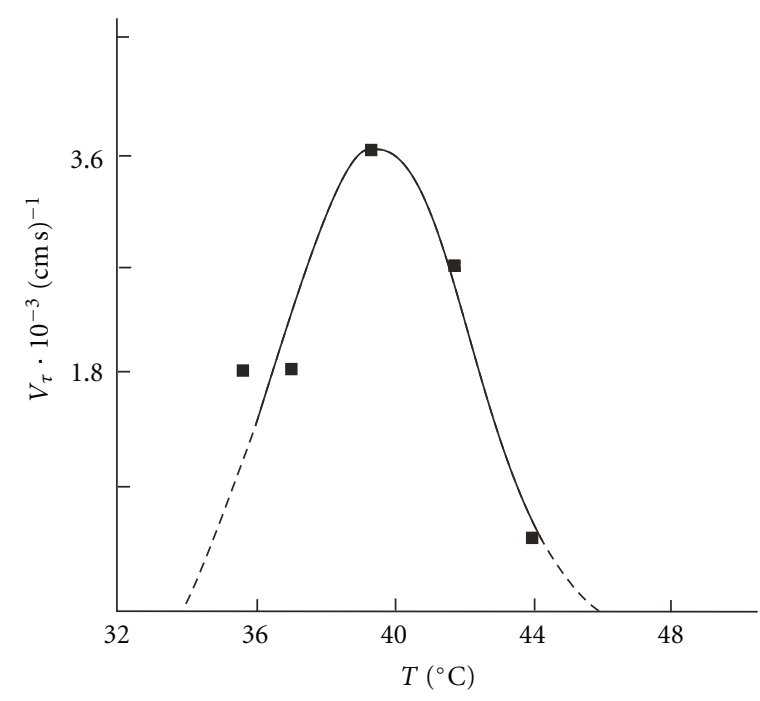

(b)

FIGURE 4: Estimation of the boundary temperatures of phase separation for the CTA-nitromethane system with a polymer concentration of $9 \mathrm{wt} \%:$ (a) by the extrapolations $V_{\tau}(T) \rightarrow 0(1)$ and $V_{\tau}^{-1}(T) \rightarrow 0(2)$ for the rate calculated from the $\tau=f(t)$ fragment of intense turbidity growth (method 1); (b) by the extrapolation $V_{\tau}(T) \rightarrow 0$ for $V_{\tau}$ determined from the initial fragment of the kinetic $\tau=f(t)$ curve $(\operatorname{method} 2)$.

( $c=$ const $)$ at extrapolation intersects the abscissa axis at the temperature of liquidus, whereas the left-hand one gives the vitrification temperature [12]. Probably, in the composition range with an extreme $V_{\tau}=f(T)$ dependence (method 2), particles with either amorphous or highly oriented structure (e.g., of crystal or LC nature) originate at the first instant of time when the system transfers to its metastable state. As the kinetics of both crystallization and LC ordering are extended in time and the viscosity of the CTA-nitromethane mixture of such compositions is rather high, the system is apparently in the metastable range with respect to these types of phase separation [14]. By virtue of these causes, relatively quick amorphous phase separation is fixed at further thermostatting. In this case, the formation and growth of new-phase centers are facilitated by the fact that the probability of appearance of the corresponding fluctuation ensembles is significantly higher because there is no need for strict geometrical packing of the segments (as is required to form crystallites) or for realization of a certain macromolecular conformation (to form LC structures). The establishment of crystal or LC equilibria (if any) within this concentration-temperature range could be expected in a longer period and at a high degree of supersaturation of the polymer-concentrated phase. 


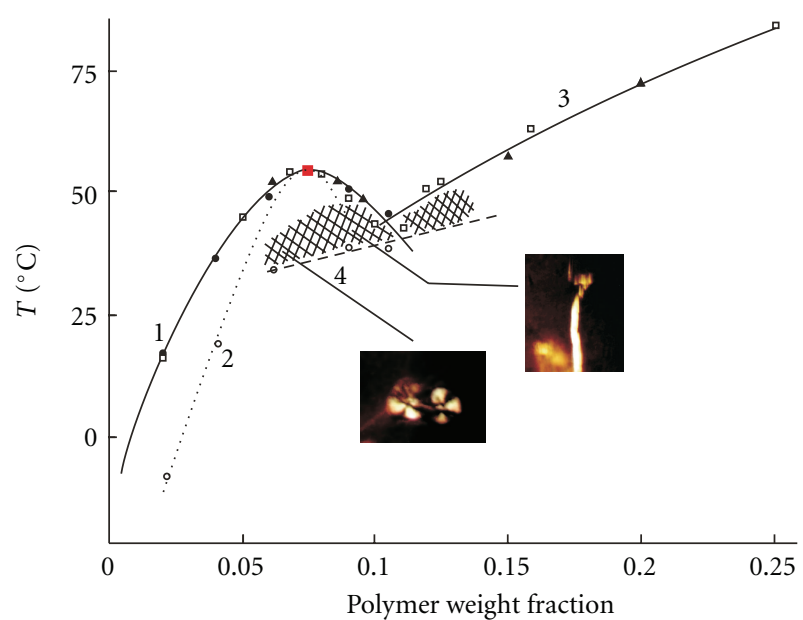

(a)

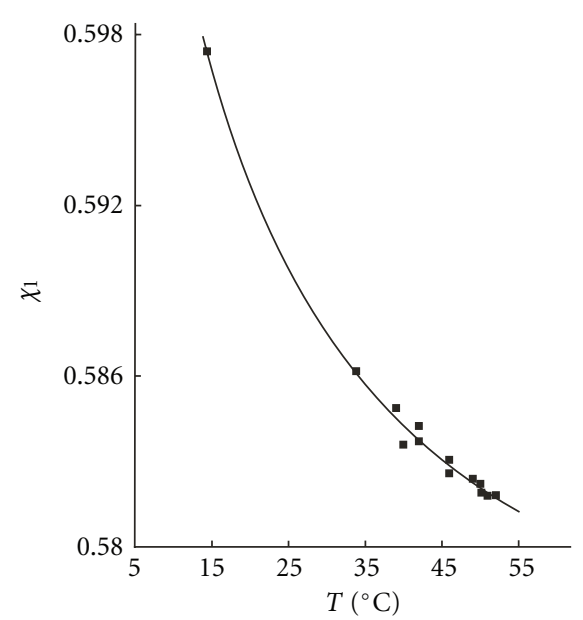

(b)

Figure 5: (a) Phase diagram of the cellulose triacetate-nitromethane system: squares denote the data of polarization microscopy, the circles are from the turbidity spectrum method (dark ones: extrapolation $V_{\tau}(T) \rightarrow 0$ by method 1 and that of the right-hand branch $V_{\tau}(T) \rightarrow 0$ by method 2; open: extrapolation $V_{\tau}^{-1}(T) \rightarrow 0$ by method 1 and that of the left-hand branch $V_{\tau}(T) \rightarrow 0$ by method 2), and the triangles mean DTA; (1), (2) the binodal (the solid line) and spinodal (the dashed line), approximated and calculated, respectively, from Flory-Huggins' theory with experimentally found compositions of the coexisting phases, (3) the liquidus, (4) the vitrification curve. The dashed area depicts the concentration-temperature range of LC state existence. Insets: the system's morphology in polarized light (see text for explanation). (b) Temperature dependence of the calculated Huggins interaction parameter $\chi_{1}$.

Having the extreme dependence of the turbidity change rate for moderately concentrated systems $(c \sim 8-10 \mathrm{wt} \%)$ as the starting point (Figure 4(b)), we can hypothesize as follows. The geometrical locus of points obtained by zero extrapolation of the right-hand branch of the extreme $V_{\tau}=$ $f(T)$ curve (method 2) or by the condition $V_{\tau}(T)=0$ (method 1) reflects the location of the binodal. The Zero extrapolation of the left-hand branch of the $V_{\tau}=f(T)$ curve apparently gives the temperature coordinates of the vitrification curve. A more detailed interpretation of this hypothesis is given below.

Separate experiments to find configurative points of the state diagram were conducted by means of DTA. The $T$ value corresponding to the minimum point of the endothermic peak on the thermogram was taken as the temperature of phase separation.

The found compositions of the phases coexisting at a certain temperature were used to approximate the binodal (see above) and to calculate the spinodal by Flory-Huggins' theory [10], as well as to estimate the interaction parameter $\chi_{1}$. The number of elementary units in a macromolecule was taken as $z=161$, and the fitted temperature dependence of $\chi_{1}$ was expressed as

$$
\chi_{1}=0.5708+\frac{0.7016}{T-261}
$$

Figure 5(a) shows our version of the phase diagram of the CTA-nitromethane system plotted as a result of our experiments, approximations, and calculations. The $\chi_{1}=f(T)$ dependence is depicted in Figure 5(b). This state diagram is characterized by a UCST with the following coordinates: critical temperature, $T_{\mathrm{cr}}=57^{\circ} \mathrm{C}$; critical concentration, $c_{\mathrm{cr}}=$ $7.3 \mathrm{wt} \%$. No LCST was detected, though the heating of the solutions in sealed ampoules was up to $200^{\circ} \mathrm{C}$, much higher than the boiling point of the pure solvent. The polarization microscopy, turbidity spectra, and DTA data are in good agreement in respect to the temperatures of phase separation round. The reproducibility and reversibility (noted above) of the temperature-concentration location of the phase transition points enable us to consider the experimental and calculated boundary curves (the binodal, spinodal, liquidus, and vitrification curve) to be equilibrium ones.

The interaction parameter $\chi_{1}$ near $T_{\text {cr }}$ tends to $\sim 0.5$, which corresponds to the regularities of the thermodynamics of solutions of semirigid polymers at amorphous phase separation. It tends to infinity at $T \rightarrow 261 \mathrm{~K}$, rather than at $T \rightarrow 0 \mathrm{~K}$ (see (2) for $\chi_{1}$ ). This temperature lies close to the melting point of nitromethane, where it loses the properties of a solvent. In other words, the energy of one nitromethane molecule is insufficient to transfer it to the medium of polymeric segments. As we see, the introduction of an additional term into the expression for $\chi_{1}$ in the first approximation of Flory-Huggins' theory seems rather reasonable.

The state diagram shown in Figure 5(a) is sophisticated, with two types of phase separation, namely, amorphous (under the binodal cupola) and crystal (below the liquidus curve 3), and a range of coexistence of various phases. This phase diagram is in fundamental accord (i.e., by phase separation types) with that obtained in [5] by the turbidity spectrum method (with the application of thermokinetic approach) for a polymer sample with close physicochemical characteristics but produced at a different industrial enterprise. The only difference is in the interpretation of the absolute instability curve obtained by the turbidity spectrum method and located (in our case, as well as in [5]) below 
the phase separation curve of the amorphous type and the initial segment of the liquidus. We divide it into the spinodal (curve 2) and the vitrification curve (curve 4).

The phase state of the system is such: at temperatures above the binodal and liquidus, all the mixtures are homogeneous transparent solutions. If the temperature is lowered and the configurative point moves to the metastable range, the CTA-nitromethane system of various concentrations may have various morphologies, depending on the polymer concentration and the distance (along the temperature axis towards lower T's) from the stability range. The state diagram contains several ranges. For low-concentrated solutions (below 3\%), under conditions of a rather high kinetic mobility of the components' molecules, quick processes of amorphous phase separation are observed with lowering temperature. They are fixed visually, for example, by the appearance of opalescence; in some cases, flocky precipitation may appear. For medium-concentrated solutions $(\mathcal{c} \sim-5.53 \mathrm{wt} \%)$ with low viscosities, the system splits into two phases in time. A Dense white precipitate is formed in the polymer-concentrated phase, and the other phase is an opalescent solution with suspended particles.

Exploring solutions with higher concentrations is hindered by the slow establishment of equilibrium and the absence of sharp interphases. For example, at amorphous stratification (inside the binodal cupola), incomplete phase separation is observed within $\sim 5.5<c<\sim 10 \mathrm{wt} \%$ because of the high viscosity, low values of the diffusion coefficient [15], the longevity of relaxation processes, and the critical retardation effect (see above). Structure formation processes are strongly influenced by the time factor, as well as by the choice of the initial temperature point. Cooling of the solutions with such concentrations down to temperatures below the compatibility curve on the state diagram is accompanied by the formation of gels with their characteristic instability. Being owing transparent at first, such gels then get turbid and undergo syneresis in time to ordering and orientation processes [16]. Such a behavior can be explained by allowing for some peculiarities of phase separation in solutions of crystallizable polymers, including CTA $[17,18]$. For such objects, a state with an amorphous type of phase separation is often realized at first, with subsequent transition to crystallization or to possible formation of an intermediate LC state.

Solutions with $c>\sim 10 \mathrm{wt} \%$ form no gels. Decreasing the temperature results in intense dimness of the system and in its transformation to a kind of paste. The higher the polymer concentration in the system and the lower the temperature inside the phase separation region, the higher the rate of this process. At room temperatures, crystallization occurs in the CTA-nitromethane system with the mentioned compositions. It is evidenced by the X-ray diffraction patterns of the films cast from such systems.

Figure 6 presents the diffraction patterns of powder CTA isolated from its nitromethane solution with concentrations 12 and $25 \mathrm{wt} \%$ (curves 1 and 2, resp.) at $22 \pm 2^{\circ} \mathrm{C}$. For comparison, we give a diffraction pattern of a CTA film cast from a methylene chloride-ethanol $(90: 10)$ mixture, which is a volatile liquid (curve 3 ). Because of the high rate of

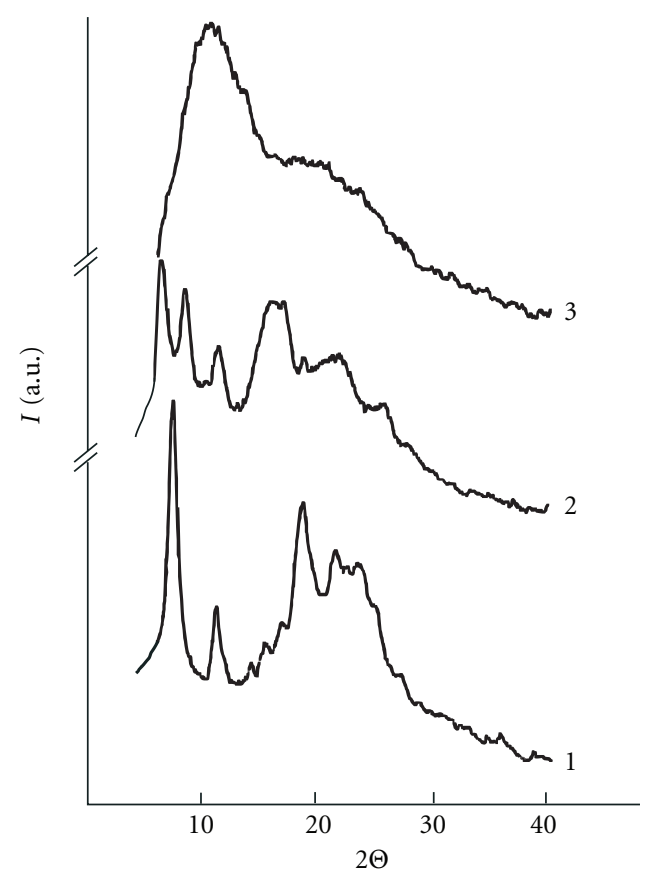

FIGURE 6: Diffraction patterns of CTA: powder isolated/precipitated from a nitromethane solution with polymer concentrations of 12 (1) and $25 \mathrm{wt} \%$ (2); a film obtained from a solution in the process solvent (methylene chloride + ethanol $(90: 10)$ ) with a concentration of $3 \mathrm{wt} \%$ (3); $T=22 \pm 2^{\circ} \mathrm{C}$.

evaporation of this mixture $(\sim 3-4 \mathrm{~h})$, the macromolecules are obviously fixed in that conformation which they had in a dilute solution (e.g., coiled). Hence, such films hafe an amorphous structure. The diffractograms of the CTA powder obtained from nitromethane solutions resemble that of crystal CTA [18].

The maximum number of intense and resolved reflexes is observed for the CTA isolated from its nitromethane solution with a lower weight concentration (Figure 6, curve 1). This can be explained by taking into account that the specific polymer-solvent interaction and kinetic factors (associated with the high viscosity, low rate of diffusion and relaxation processes, etc.) promote better contact between the chains along the nonsolvated segments of the polymeric macromolecules. When the solvent is evaporated (the configurative point isothermally goes right along the composition axis), the macrochains become ordered and a rightly oriented phase is accumulated, and then fixed on complete solvent removal. Naturally, the diffraction patterns of the CTA powder isolated from a solution with a higher concentration (i.e., more distant along the concentration axis at the early stage of phase separation) show less intense reflexes (curve 2).

The fact of high-crystalline CTA isolation from its dilute solutions (including nitromethane ones) is well known [1719]. Highly acetylated CTA is a polymer of regular structure with sufficiently homogeneous distribution of acetate groups along the macromolecular chain. The higher the acetylation degree of a sample, the more crystallizable this sample is [19]. The molar fraction of crystallizing units in this polymer 


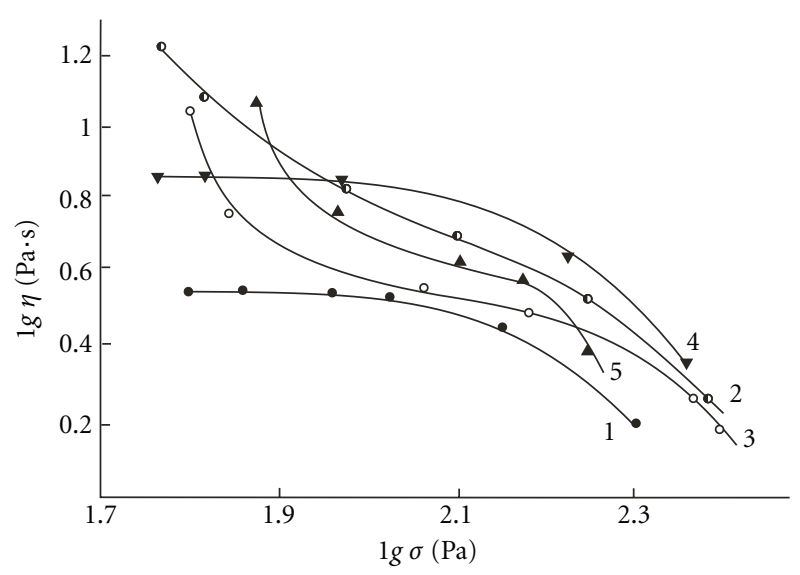

(a)

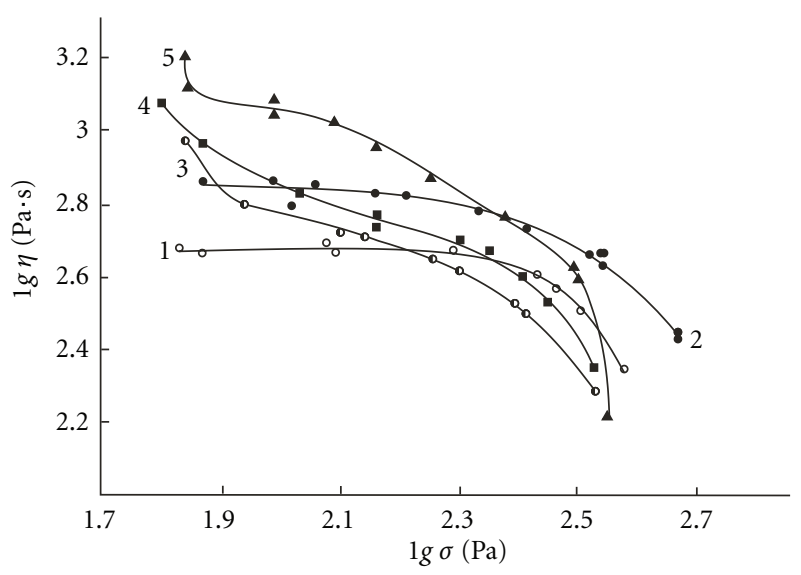

(b)

Figure 7: Flow curves of the CTA-nitromethane system with polymer concentrations of (a) 6 wt $\%$ at $T=60^{\circ}(1), 43^{\circ}(2)$, and $35^{\circ} \mathrm{C}(3)$, and $8 \mathrm{wt} \%$ at $60^{\circ}(4)$ and $40^{\circ} \mathrm{C}(5)$. The duration of thermostatting, $1 \mathrm{~h}$; (b) $13 \mathrm{wt} \%$ at $50^{\circ}(1), 45^{\circ}(2), 38^{\circ}(3), 30^{\circ}(4)$, and $25^{\circ} \mathrm{C}(5)$, the duration of thermostatting $1 \mathrm{~h}(1,2), 2 \mathrm{~h}(3-5)$.

calculated according to Flory [10] was 0.92 for the CTA sample under study.

It is natural to suppose that at lowering temperature, crystal precipitation of CTA from its nitromethane solutions will be the final stage of phase separation for the solutions under study. However, as this process is extended in time, every stage of phase transformations will show a variety of physical states, structural and morphological forms of the polymer.

Our rheological studies of the CTA-nitromethane system have shown that classical flow curves (usual for polymeric solutions) with regions of the maximum Newtonian viscosity (below $\lg \sigma \sim 2-2.2(\mathrm{~Pa})$ ) and structural viscosity (Figure 7(a), curves 1 and 4; Figure 7(b), curves 1 and 2) are observed in the thermodynamic miscibility range. In the concentration-temperature range under the binodal and the liquidus curve, the flow character and, hence, the shape of viscosity rheograms change. As the rheokinetics of phase transitions in the CTA-nitromethane system is discussed in [20] in detail, we now dwell on some peculiarities of the rheological behavior, reflecting changes in the phase state of the system.

For the range $5.5<c<10 \mathrm{wt} \%$ at lowering temperature and of the crossing of the binodal, rheological curves characteristic of structured gellike systems are realized (Figure 7(a), curves 2,3 , and 5 ). In the region of relatively small shear stresses, a sharp increase in viscosity occurs, which speaks for the appearance of structures with an ultimate strength. This manifests itself as continuous lowering of $\eta$ in the whole $\sigma$ range and as the absence of a region of constant viscosity on the flow curves. Besides, in a certain temperature range there occurs such an intense drop in viscosity that it becomes lower than its value corresponding to a higher temperature, that is, the homogeneous solution range (see, e.g., curves 4 and 5). Such a viscosity drop cannot be explained only by gel formation; it testifies to a change in the flow mechanism, where the appearing structures possess lower resistance. It is natural to suppose that the decrease in $\eta$ is caused by the formation of a highly ordered phase whose viscosity may be much lower than that of the isotropic phase [21,22]. Similar data have also been obtained for many rigid-chain synthetic polymers at the transition of their solutions from isotropic to LC state [21, Pages160-165].

Cellulose acetates belong to the class of linear polymers with enhanced chain rigidity and a high asymmetry degree [22]. Spontaneous transition to an LC state is possible for them under certain thermodynamic conditions, which has been confirmed in the literature [23-25]. The possibility of transition of the CTA-nitromethane system to an LC phase is also supported by $[13,26]$; the effect of spontaneous elongation of CTA-based fibers and films in nitromethane vapor [3, 27-29] speaks for this as well. We note that the selective solvation of the residual $\mathrm{OH}$ groups in CTA with nitromethane predetermines the realization of rather rigid, extended helical conformations of macromolecules [27, 29]. According to [30], structure formation in such a polymer could go through a stage of LC ordering.

The rheologically based temperature dependences of viscosity have a maximum peculiar to LC systems (Figure 8, curves $\left.1^{\prime}-2^{\prime \prime}, 3\right)$. Such character of the temperature dependence of viscosity was also observed in studying the rheokinetic regularities of phase separation in the CTAnitromethane system with relatively low shear stresses $(\lg \sigma<$ $1(\mathrm{~Pa}))$ on a Heppler viscometer. The lower the temperature inside the found range of mesophase formation, the higher the rate of formation of highly oriented structures. All this gives evidence for a spontaneous process of CTA macromolecular ordering, with the factor of external impacts apparently playing merely a stimulating role in structural self-organization.

The formation of an anisotropic phase was observed with an optical microscope in crossed Polaroids as well (i.e., with no shear deformations applied). Birefringent supramolecular structures appeared in the temperature range of the anomalous drop in $\eta$. For example, helicoidal (in the form of twisted ribbons) anisometric structures and even anisotropic 


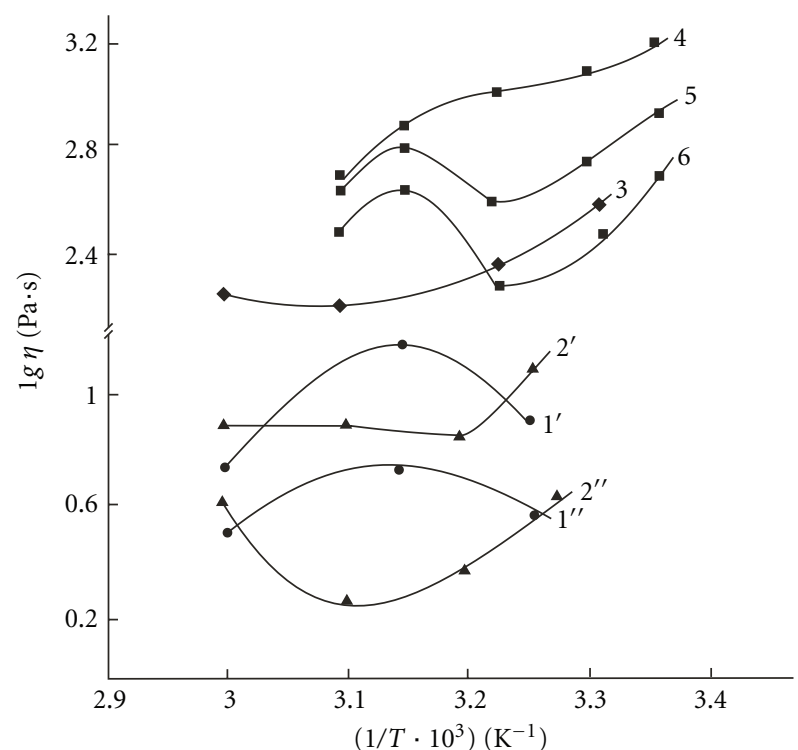

FIGURE 8: Dependence of viscosity on the inverse temperature for a nitromethane solution of CTA with polymer concentrations of 6 $\left(1^{\prime}, 1^{\prime \prime}\right), 8\left(2^{\prime}, 2^{\prime \prime}\right), 9 \mathrm{wt} \%(3)$, and $13 \mathrm{wt} \%(4,5,6)$ at the following shear stresses $(\lg \sigma,(\mathrm{Pa})): 1.8\left(1^{\prime}, 2^{\prime}, 4\right), 2.1(3), 2.2\left(1^{\prime \prime}, 2^{\prime \prime}, 5\right)$, and 2.5 (6).

drops crossed with a Maltese cross (see insets in Figure 5(a)) were observed. All the optically active structures were mobile; turning the object table of the polarization microscope by $40-50^{\circ}$ led to the disappearance of their images. The reversibility of the anisotropic phase formation was established in the cooling-heating cycle without shearing.

Precipitation of these LC-related structures with, for example, ethanol results in the formation of fibrous precipitates (Figures 10(a)-10(c)), which also confirms the realization of an LC phase [21, Pages 100-107]. The fresh sediment is optically anisotropic (Figure 10(a)). Electron microscopic images of the CTA precipitate isolated from an anisotropic solution by means of spraying onto mica and shaded with carbon show its morphology as elongated chaotically oriented fibrils (Figure 10(d)) [20].

The observed indications of supramolecular orientation of the structural elements (Figures 9 and 10) give evidence of the helicoidal ordering of the LC phase in the CTAnitromethane system. On the basis of our results and the literature data on studying the LC state in solutions of cellulose derivatives $[23-25,31,32]$, the LC ordering type in the said system can be characterized as cholesteric.

No anomalous rheological curves and no extremum on the $\lg \eta=f\left(T^{-1}\right)$ curve were obtained when $c<5.5 \mathrm{wt} \%$. Within $11<c<14 \mathrm{wt} \%$ in a narrow temperature range between the liquidus and the vitrification curve (Figure 5, curves 3 and 4), all the above peculiarities of rheological behavior were observed, namely, the anomalous drop in viscosity (Figure 7(b), curve 3-5) and the nonlinearity of the temperature dependence of $\eta$ (Figure 8, curves 5 and 6). However, the critical stresses above which plastic flow of the system and a maximum on the $\lg \eta=f\left(T^{-1}\right)$ curve were observed were higher for the given range. When $\sigma$ was lower than its critical value, $\eta$ increased with decreasing $T$ (Figure 8, curve 4). As well as for the low-concentrated systems (curves $1^{\prime}-2^{\prime \prime}$ ), the higher was $\sigma$, the more pronounced was the peak on the $\lg \eta=f\left(T^{-1}\right)$ (curves 5 and 6). Such behavior is typical of LC solutions of many cellulose derivatives $[22,23,25]$ and other synthetic rigidchain polymers [21]. This can be explained by hypothesizing viscosity anisotropy, that is, the dependence of internal friction on the orientation of the macromolecules' long axes along the direction of the flow [33]. Viscosity rose with no limit in the temperature range below the vitrification curve, up to the system's transition to a nonflowing state.

Obtaining reliable information on the morphological properties of a system with the polymer concentration above $14 \mathrm{wt} \%$ and below the liquidus temperatures is rather difficult. When being cooled, such systems quickly get turbid and pass into a pastelike substance. This may be caused either by the formation of LC structures or by the crystallization process.

Our experimental data allowed the concentrationtemperature field of LC state formation in the CTAnitromethane system to be determined (dashed partition on the phase diagram, Figure 5(a)). One can notice its narrowness in both variables (temperature and concentration), which is in accord with Flory's theoretical concepts [34] and experimental studies on other systems of the cellulose ether/ester-solvent type [21-23]. It is interesting that the threshold concentration $(\sim 5.5 \mathrm{wt} \%)$, that is, the value from which anomalous viscosity rheograms, critical shear stresses, anisotropic effects, and so forth are observed was confirmed by calculations as well. The asymmetry degree calculated by [21] for the most acetylated CTA is $\sim 140$, which corresponds (according to [34]) to a weight polymer concentration of $5.7 \%$. Beginning with the latter value, an LC phase can be formed in CTA solutions.

The absence of any LC structures in the top part of the binodal cupola, somewhat below its right-hand branch, attracts attention. This may be caused by the fact that as temperature increases, the chain rigidity diminishes and becomes lower than the critical value necessary for LC phase formation. This effect was confirmed in special experiments to study the hydrodynamic properties of dilute solutions of CTA samples with various $\bar{M}_{\eta}$ obtained by fractionation of the source polymer.

Our detection and location (in concentration-temperature coordinates) of the boundaries of LC phase formation in the CTA-nitromethane system allow the essentially different character of the temperature dependence of the turbidity kinetics for $c \sim 8-10 \mathrm{wt} \%$ (see above and Figure 4) to be explained. Whereas at the first stage (the induction period) the temperature dependence of the $\tau$ growth rate goes through a maximum (as for liquid-crystal phase separation), at the subsequent stage this rate increases with temperature monotonically as for liquid-liquid phase separation. In particular, when the temperature is lowered, the rate may vanish during the induction period and may tend to huge values (theoretically, to infinity) after this period. 


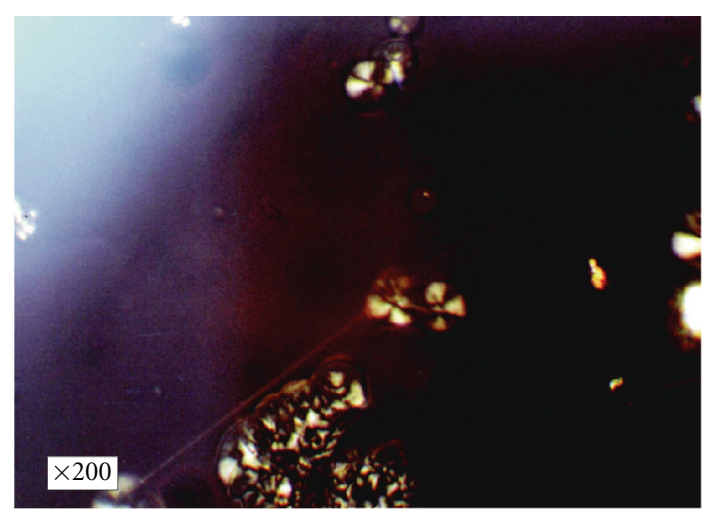

(a)

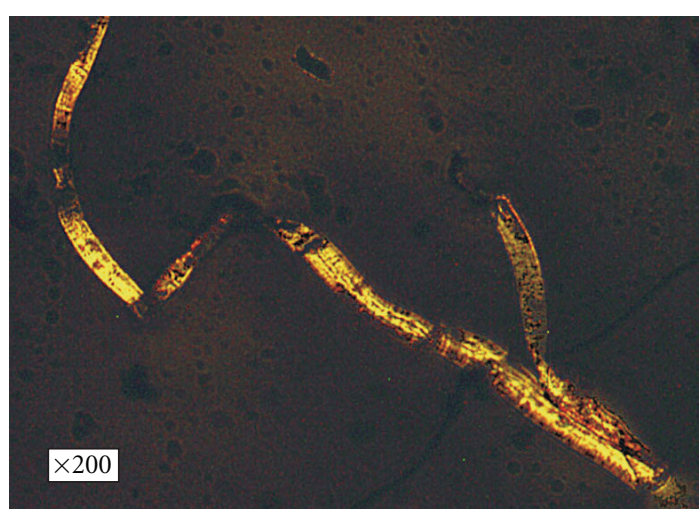

(b)

FIgURE 9: Photos of the CTA-nitromethane system in polarized light with no shear deformations applied: (a) denotes the mixture with $C$ $=6 \mathrm{wt} \%$ at $T=35^{\circ} \mathrm{C}$; (b) $C=9 \mathrm{wt} \%$ at $T=45^{\circ} \mathrm{C}$.

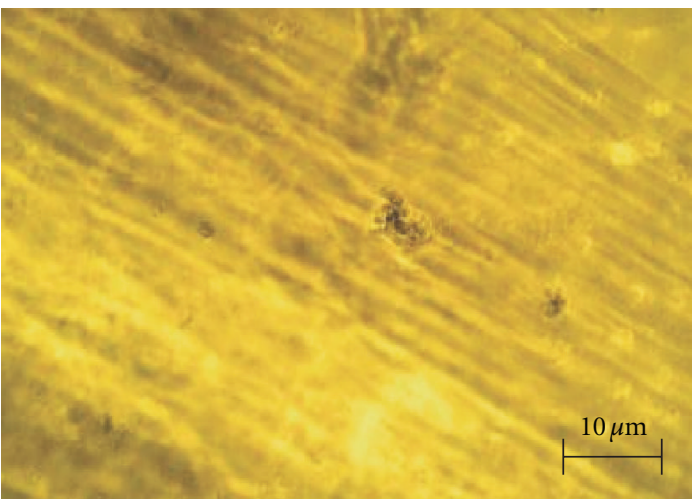

(a)

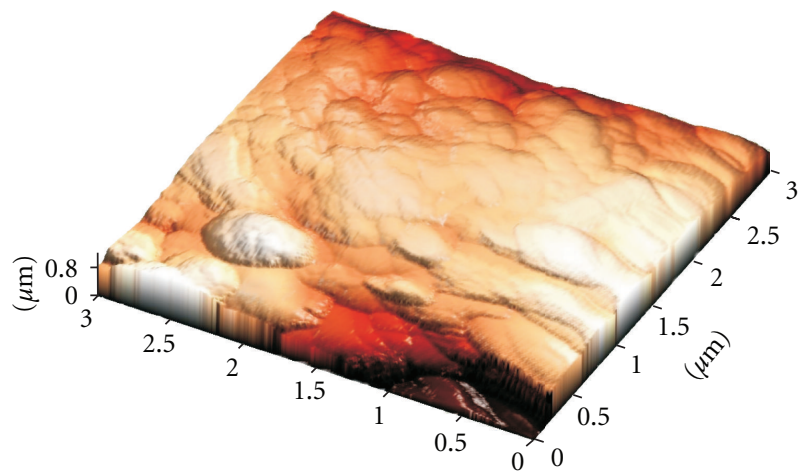

(c)

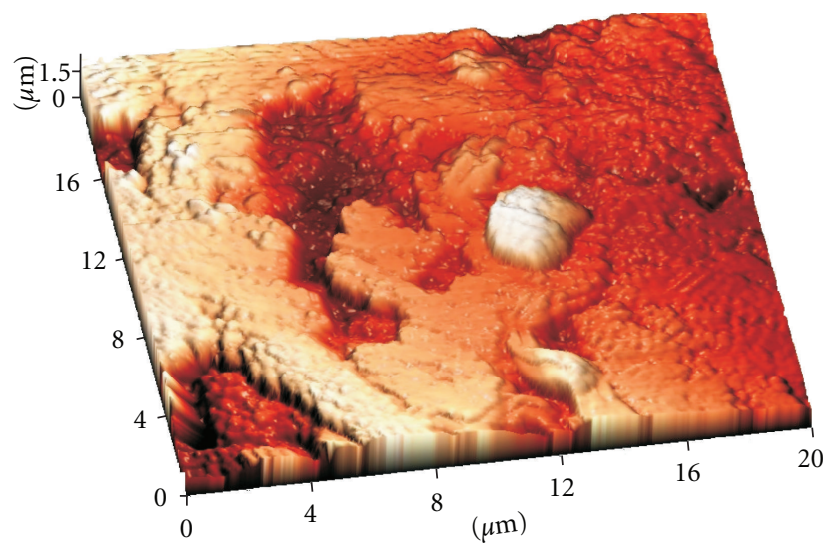

(b)

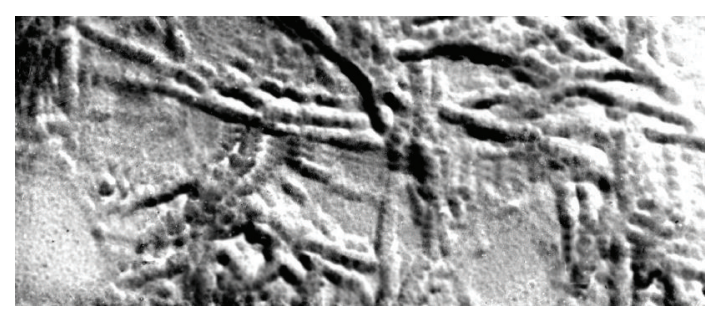

(d)

Figure 10: Morphology of the sediment obtained from the anisotropic CTA—nitromethane system by precipitation to ethanol (a)-(c) and by spraying onto mica (d): (a) is the structure of the source sediment in polarized light under crossed Polaroids; (b), (c) are the topographical image (scanning microscopy) of the surface $(20 \times 20$ and $3 \times 3 \mu \mathrm{m}$, resp.) of the same sediment (a) dried at room temperature; (d) is the structure of the sprayed sediment (electronic microscopy).

As is known, the LC state combines liquid and solid properties: there exists long-range order in one direction on the bases of rigid bonds, whereas other direction(s) may provide free sliding of layers, that is, short-range order, as in a liquid. If we hypothesize the appearance of LC particles rather than true crystallites as a disperse phase corresponding to the right-hand branch of the binodal at phase separation, then, apparently, non-full-dimensional centers (e.g., onedimensional ones for a nematic, two-dimensional ones for a smectic) must appear at first. Their formation obeys all 
the regularities of crystallization. When the temperature is decreased, the configurative point crosses the LC liquidus. Extrapolation to the zero rate gives the temperature at which the heat movement in the corresponding directions is frozen so as to prevent the macromolecules acquiring the conformations necessary for the appearance of LC centers. If we considered full-dimensional crystalline centers, such a temperature would mean full loss of macromolecular mobility and vitrification of the polymer. However, since free dimension(s) is/are available, the process continues.

After the appearance of LC centers in some way, their further growth proceeds by other free dimensions (two for a nematic, one for a smectic), that is, preferably in one or two possible directions "sideways". The centers serve as a matrix for substance accumulation and easily orient the approaching chains with the need neither in the random appearance of the necessary conformation nor in the strict geometrical packing of segments. In this respect, the sideways growth is like liquid-liquid phase separation (except the induction period, of course). One can see that all the regularities of the corresponding kinetics are observed. As temperature decreases, the turbidity growth rate monotonically increases up to huge values, which enables extrapolation to infinity. Whereas the heat movement in some dimensions of the center is frozen down to stopping its growth in "breadth" (by crystal order), the heat movement in the other dimensions appears to be enough for providing high rates of the "sideways" growth (by liquid order).

In view of all our experiments and calculations, the above discussion, and the results of the works [34-37], one can assume that bringing the configurative point to the dashed area in Figure 5(a), between the binodal cupola and the vitrification curve, results in equilibrium between the isotropic and the LC phases. Bringing it below the liquidus would give LC-crystal equilibrium. In accordance with the principle of phase equilibria independence, the appearance of LC structures under the binodal occurs in the metastable (by theamorphous equilibrium) state. Naturally, the phases corresponding to LC ordering disappear after the final equilibrium is reached.

The unusual location of the LC state region in the concentration-temperature field of the phase diagram (Figure 5(a)) may have been caused by two factors. One is the specificity of the polymer-solvent interaction, which manifests itself in the variety of physical states: homogeneous and anisotropic solutions, gels, visually observed biphasic systems, and so on. The other is superposition of different types of phase separation. To the best of our knowledge, their state diagram is the first experimental confirmation of Papkov's hypothetical phase diagram [35], combining amorphous, LC, and crystal equilibria. The only difference is that the LC and crystal (partly) equilibria are inside the liquid-liquid phase equilibrium. Hence, the relations between the coexisting phases are understandable. At the same temperature (a constant $\chi_{1}$ ), the lowest concentration of the equilibrium isotropic phase is peculiar to the liquid (amorphous) equilibrium. Therefore, the equilibrium concentration of the isotropic phase for the LC equilibrium is lower than the concentration of the same phase for the crystal equilibrium. It is quite probable that the narrow corridor of coexistence of the isotropic and anisotropic phases (replacing the wide biphasic range "isotropic solution + LC"), which follows from Flory's calculations for rigidchain macromolecules [34] (with Frenkel's supplement for semirigid chains to allow for their specific interaction with the solvent [36]) and separates the biphasic region from the single-phase LC region (not specified in this article), is sharply skewed towards higher polymer concentrations. Taking into account the decrease in the CTA macromolecular rigidity with increasing temperature, this corridor may be expected to degenerate into a bend on the binodal.

In spite of the sophisticated character of the state diagram obtained, it obeys Gibbs' phase rule and the corresponding theoretical predictions $[35,38,39]$, and it specifies the physical state of the polymer (insufficiently interpreted in [5]), corresponding to the boundaries separating the biphasic fields from the isotropic solution for all the three types of phase separation identified. Note also that the possibility of transition of cellulose esters to a crystal state through an LC phase was suggested in [37]. Though some results of this work were questioned and disputed, the general conclusion therein was supported in [35]. We finally note that with the exception of $[35,37]$, no papers are known to us in which models quantitatively describing the LC transition in cellulose derivative solutions have been presented.

\section{Acknowledgments}

The authors are indebted to Professor V. J. Klenin and the late Dr. G. N. Timofeyeva for the fruitful discussions of their results. They are thankful to Mr. D. N. Tychinin for his aid in the paper preparation.

\section{References}

[1] A. E. Chalykh, V. K. Gerasimov, and Y. M. Mikhailov, Diagrams of the Phase State of Polymeric Systems, Yanus-K, Moscow, Russia, 1998.

[2] V. J. Klenin, Thermodynamics of Systems Containing FlexibleChain Polymers, Elsevier, Amsterdam, The Netherlands, 1999.

[3] A. B. Shipovskaya and G. N. Timofeeva, "The liquidcrystalline state of cellulose acetates: from past to present. Experience of the Saratov school," Fibre Chemistry, vol. 38, no. 1, pp. 17-21, 2006.

[4] G. N. Timofeyeva, E. S. Sveshnikova, and A. B. Shipovskaya, "The orientation phenomena in system acetate of cellulose of different degree of replacement-nitromethane," in Proceedings of the Composite-2004 International Conference, pp. 336341, SGTU Press, Saratov, Russia, 2004.

[5] G. N. Timofeyeva, V. M. Averianova, and V. J. Klenin, "Thermokinetic studying of phase division in system triacetate cellulose-nitrometan," Vysokomolekulyarnye Soedineniya B, vol. 19, no. 1, p. 7, 1977.

[6] V. J. Klenin, S. Yu. Shchyogolev, and V. I. Lavrushin, Characteristic Functions of Light Scattering of Disperse Systems, Saratov State University, Saratov, Russia, 1977.

[7] C. Reichardt, Solvents and Solvent Effects in Organic Chemistry, VCH, Weinheim, Germany, 1988. 
[8] W. R. Moor and J. Schuttlewort, "Solvation of cellulose derivatives," Journal of Polymer Science B, vol. 132, no. 1, pp. 89-91, 1964.

[9] A. S. Buntjakov and V. M. Averyanova, "Structure of solutions and films of cellulose acetate," Journal of Polymer Science Part C, no. 38, pp. 109-120, 1972.

[10] P. J. Flory, Principles of Polymer Chemistry, Cornell University Press, Ithaca, NY, USA, 1953.

[11] S. L. Shmakov, "Phase equilibrium in solutions of star-shaped macromolecules: an improved Okada-Numasawa model," Polymer, vol. 43, no. 4, pp. 1491-1495, 2001.

[12] V. I. Klenin, I. V. Fedusenko, and Y. I. Klokhtina, "Structure of crystallizable polymers in solutions: effect of dissolution technique," Vysokomolekularnye Soedineniya, vol. 45, no. 12, pp. 2054-2062, 2003.

[13] A. E. Chalykh, U. V. Nikulova, and A. S. Nikulov, "Phase balance and phase structure in system polystyrene-polivinilmetilovyj an ether," Chemistry and Chemical Technology, vol. 51, no. 12, pp. 28-32, 2008.

[14] S. P. Papkov, Physicochemical Principles of Processing Polymer Solutions, Chimiya press, Moscow, Russia, 1971.

[15] A. B. Shipovskaya and G. N. Timofeyeva, "Peculiarities of phase separation in the variacetylated cellulose acetatemesophasogenic solvent (nitromethane) system," in Struktura i Dinamika Molekuliarnykh Sistem, vol. 10, part 2, pp. 222225, Kazan University Press, Kazan, Russia, 2003.

[16] P. V. Kozlov and E. V. Gert, "Individual crystals of cellulose acetates," in Chemistry and Technology of Cellulose Derivatives, pp. 156-160, MITXT press, Moscow, Russia, 1971.

[17] A. Kuppel, H. Bittiger, and E. Husemann, "Das faserdiagramm des Triacetylcellulose-Nitromethankomplexes," Kolloid-Zeitschrift und Zeitschrift für Polymere, vol. 250, no. 6, pp. 623-624, 1972.

[18] P. Messien, "Cristallinite des acetates et triacetates de cellulose," Bulletin de la Société Royale des Sciences de Liége, vol. 37, no. 9-10, pp. 445-454, 1968.

[19] A. B. Shipovskaya, G. N. Timofeeva, N. O. Gegel, and S. Yu. Shchegolev, "Phase separation and liquid-crystal state of cellulose triacetate in nitromethane," Journal of Engineering Physics and Thermophysics, vol. 81, no. 6, pp. 1222-1231, 2008.

[20] S. P. Papkov and V. G. Kulichikhin, Liquid Crystal State of Polymers, Khimiya press, Moscow, Russia, 1977.

[21] V. G. Kulichikhin and L. K. Golova, "Liquid crystalline state of cellulose and its derivatives," Chemistry of Wood, vol. 5, pp. 9-27, 1985.

[22] V. V. Myasoyedova, S. Y. Belov, and G. A. Krestov, "Relations between rheological properties and phase transitions in nonaqueous solutions of cellulose triacetate and cellulose in the trifluoroacetic acid-1,2-dichloroethane mixture," Vysokomolekulyarnye Soedineniya A, vol. 29, no. 6, pp. 1149-1152, 1987.

[23] B. Y. Yunusov, O. A. Khanchich, M. V. Shablygin, O. A. Nikitina, and A. T. Serkov, "Structural transformations at solidifying anisotropic solutions of cellulose acetates in trifluoroacetic acid," Vysokomolekulyarnye Soedineniya B, vol. 25, no. 4, pp. 292-294, 1983.

[24] G. H. Meeten and P. Navard, "Gel formation and liquid crystalline order in cellulose triacetate solutions," Polymer, vol. 24, no. 7, pp. 815-819, 1983.

[25] S. M. Aharoni, "Rigid backbone polymers-8. Effects of the nature of the solvent on the lyotropic mesomorphicity of cellulose acetate," Molecular Crystals and Liquid Crystals, vol. 56, no. 7, pp. 237-241, 1980.
[26] G. N. Timofeeva and V. M. Averianova, "Studying kinetics phase division in student not forming system triacetate cellulose-nitrometan a rheological method," Colloid Journal, vol. 42, no. 2, pp. 393-397, 1980.

[27] A. B. Shipovskaya, S. L. Shmakov, and G. N. Timofeeva, "Phase processes and energetics of spontaneous change in the dimensions of acetate fibers in nitromethane vapors," Polymer Science-Series A, vol. 48, no. 5, pp. 509-519, 2006.

[28] A. B. Shipovskaya and G. N. Timofeeva, "New information concerning spontaneous elongation of acetate fibers," Polymer Science-Series A, vol. 49, no. 11, pp. 1210-1217, 2007.

[29] A. B. Shipovskaya and G. N. Timofeeva, "Self-organizing a macropierkul of cellulose acetates under the influence of steams of mezofazogen solvents," in Sinergetika $v$ Estestvennykh Naukakh, N. O. Gegel and S. Yu. Shchyogolev, Eds., pp. 178-181, TverGU Press, Tver Cuty, Russia, 2008.

[30] S. Y. Frenkel, V. G. Baranov, B. M. Ginzburg, and G. K. Eliashevich, "Specific interactions polymer-solvent at crystallization and occurrence of a supramolecular order," Doklady Akademii Nauk SSSR, vol. 179, no. 5, pp. 1155-1158, 1968.

[31] H. Song, Y. Niu, Z. Wang, and J. Zhang, "Liquid crystalline phase and gel-sol transitions for concentrated microcrystalline cellulose (MCC)/1-ethyl-3-methylimidazolium acetate (EMIMAc) solutions," Biomacromolecules, vol. 12, no. 4, pp. 10871096, 2011.

[32] D. D. Grinshpan, T. A. Savitskaya, N. G. Tsygankova et al., "Cellulose acetate sulfate as a lyotropic liquid crystalline polyelectrolyte: synthesis, properties, and application," International Journal of Polymer Science, pp. 1-17, 2010.

[33] V. G. Kulichikhin, G. I. Kudryavtsev, and S. P. Papkov, "Rheological properties of liquid-crystalline polymer solutions," International Journal of Polymeric Materials, vol. 9, no. 3-4, pp. 239-256, 1982.

[34] P. J. Flory, "Phase equilibria in solutions of rodlike particles," Proceedings of the Royal Society A, vol. 234, no. 1, pp. 60-72, 1956.

[35] S. P. Papkov, "About a mutual combination liquid, liquid crystal and crystal phase balance in connection with a problem of morphology of natural polymers," Vysokomolekulyarnye Soedineniya A, vol. 26, no. 5, pp. 1083-1089, 1984.

[36] S. Y. Frenkel, "Thermokinetics of formation of ordered structures in polymer solutions and gels," Pure and Applied Chemistry, vol. 38, no. 1-2, pp. 117-149, 1974.

[37] A. Ciferri and W. R. Krigbaum, "Self-assembly of natural polymers via liquid crystalline phases," Molecular Crystals and Liquid Crystals, vol. 69, no. 3-4, pp. 273-280, 1981.

[38] W. Hu, D. Frenkel, and V. B. F. Mathot, "Lattice-model study of the thermodynamic interplay of polymer crystallization and liquid-liquid demixing," Journal of Chemical Physics, vol. 118, no. 22, pp. 10343-10348, 2003.

[39] A. Y. Grosberg and A. R. Khokhlov, Statistical Physics of Macromolecules, Nauka press, Moscow, Russia, 1989. 

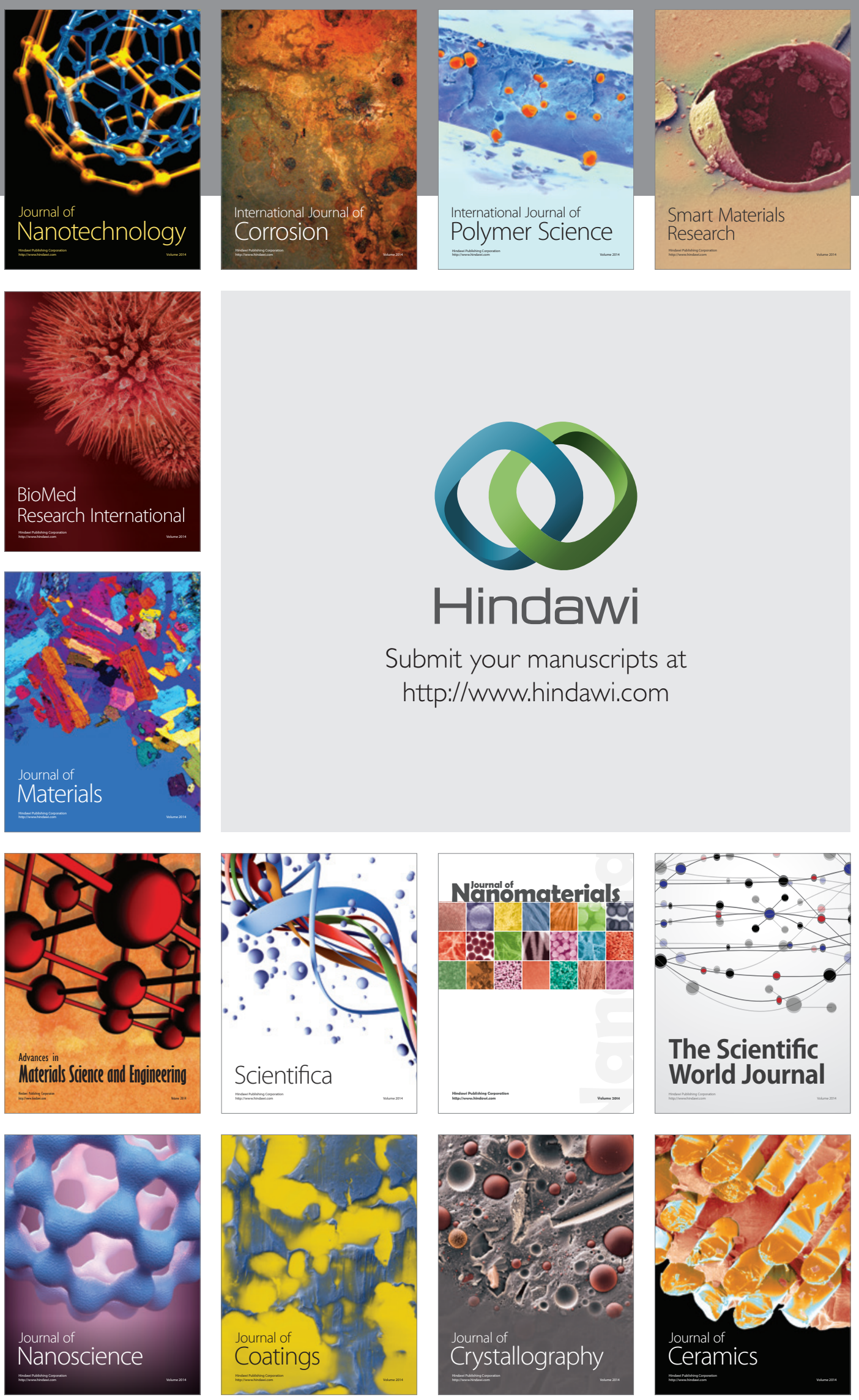

The Scientific World Journal

Submit your manuscripts at

http://www.hindawi.com

\section{World Journal}

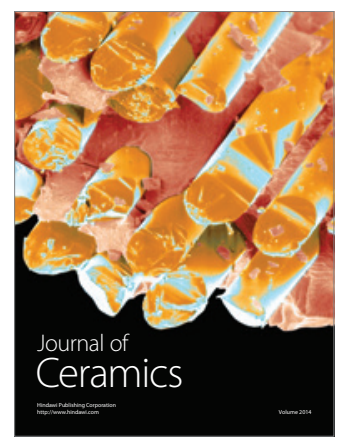

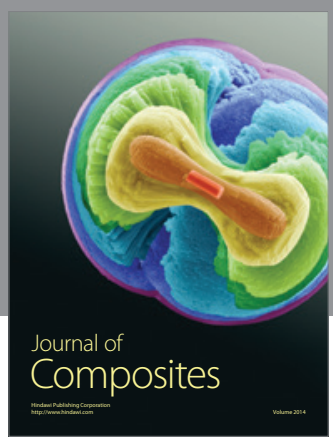
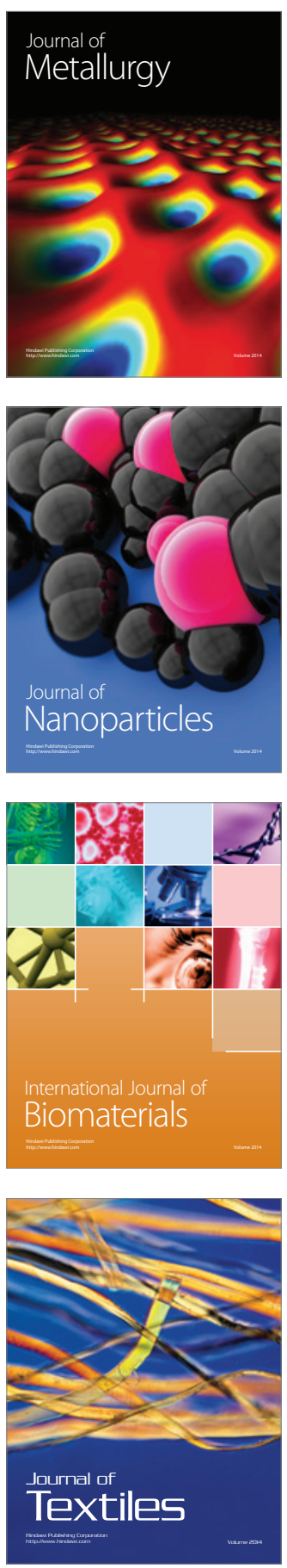